Miloš D. Đurić

Elektrotehnički fakultet

Univerzitet u Beogradu
UDC: $371.3:: 811.111]: 004$

DOI: $10.18485 /$ dh.2015.2.ch23

\title{
POWER POINT PROJEKTI U ENGLESKOM ZA ELEKTROTEHNIKU I SOFTVERSKO INŽENJERSTVO
}

\begin{abstract}
Sažetak
Nakon uvođenja promena u nastavnom programu u širem smislu i nastavnom programu u užem smislu u engleskom jeziku za elektrotehniku i softversko inženjerstvo, kao i nakon implementacije ovih izmena, uveden je novi vid vrednovanja i evaluacije komunikativne performanse studenata u obliku Power Point projekata.

Preciznije, u ovom radu se opisuje struktura i primena Power Point projekata koji su po meri studenata, a osmišljeni su da se aktivno uvedu u nastavu engleskog za elektrotehniku i softversko inženjerstvo nakon sprovedene opsežne i sveobuhvatne analize potreba. Konstatovali smo da Power Point projekti predstavljaju jednu alternativnu iskustvenu simulaciju u okviru engleskog jezika struke na visokoškolskom nivou.

$U$ radu opisujem promene koje sam izvršio uvođenjem novih predmeta na Elektrotehničkom fakultetu u Beogradu. Zatim se osvrćem na neophodnost poboljšanja komunikativne performanse studenata, čime se uviđa relevantna uloga studentskih projekata u obliku Power Point prezentacija na stručnu temu na engleskom jeziku struke. Opisuje se istraživanje koje autor sprovodi više od decenije rada na Elektrotehničkom fakultetu u Beogradu, a koje se odnosi na segment poboljšanja komunikativne performanse u oblasti engleskog za elektrotehniku i engleskog za softversko inženjerstvo.

Ključne reči: Power Point projekti, Power Point prezentacije, engleski za elektrotehniku, engleski za softversko inženjerstvo, komunikativna performansa, veb alati, ekspertski sistemi.
\end{abstract}

\subsection{Uvodna razmatranja}

Prema literaturi, danas se obrazovanje suočava sa neophodnošću da se adaptira životnom okruženju u kome se konstanto uvećava tehnološki napredak (Cox 2008: 1), a svaki deo obrazovanja zavisi od ostalih delova 
i ima smisla u vezi sa drugim delovima (Langran 1970: 86). U tom smislu, nastava engleskog jezik struke nije izuzetak, te postoji potreba da se i ona uključi u nove trendove, tokove i inovacije u nastavi. Ove inovacije odnose se, između ostalog i na projekte koji bi se mogli posmatrati kao svojevrsne simulacije, a u obliku su Power Point prezentacije. To i nije iznenađujuće, s obzirom na to da su predavanja u vidu Power Point-a postala integralni deo načina izvođenja nastave u većini institucija (Burke and James 2008: 277). U literaturi se konstatuje da je elektronski način predavanja (tj. elektronska predavanja), bilo kao dodatak tradicionalnom vidu nastave ili načinu učenja na daljinu, predstavlja ogromne mogućnosti u fakultetskom obrazovanju (Griffin, Mitchell and Thomson 2009: 532).

$U$ nastavi engleskog jezika struke, simulacije u vidu Power Point projekata predstavljaju dragocenu integraciju jezičkih elemenata, ali i elemenata koji dolaze iz nastave struke koja se izučava na fakultetu, u mom slučaju, predmetnog sadržaja iz elektrotehnike i softverskog inženjerstva. Pored toga, veoma su važne jezičke veštine, ali i veštine koje se usvajaju iz stručnih predmeta (iz oblasti elektrotehnike i softverskog inženjerstva), a koje se promovišu putem raznovrsnih standarda i preporuka u obrazovnom kontekstu XXI veka. Sem toga, ove veštine se usvajaju putem specifične interakcije primenjene putem ispunjavanja pedagoških aktivnosti koje se razvijaju sa ciljem da se verno preslikaju profesionalni zadaci koji dolaze iz autentičnog poslovnog okruženja u kome će raditi budući inženjeri elektrotehnike i softverskog inženjerstva.

$\mathrm{U}$ literaturi se konstatuje da uprkos tome što postoje ograničenja klasičnih univerzitetskih predavanja, ona ipak ostaju dominantna u univerzitetskom rasporedu časova, pa je stoga sposobnost konstruktivne upotrebe vremena tokom predavanja važna akademska veština za većinu studenata (Huxham, 2010: 1). Autori konstatuju da Power Point pomaže u organizovanju jasnog, konciznog i potpunog predavanja od početka do kraja (Adams 2006: 394).

Prema relevantnoj literaturi, Power Point je softverski alat koji je postao glavno sredstvo za prezentacije u univerzitetskim slušaonicama, konferencijskim salama i u okviru računarski zasnovane obuke (Savoy, Proctor and Salvendy, 2009: 858). U literaturi se konstatuje da je Power Point softver, obuhvaćen paketom Majkrosoft ofisa (eng. Microsoft Office) 
jedan moćan alat za prezentacije (Szabo and Hastings 2000: 175). Može se reći da ovaj softverski alat u izvesnoj meri čini predavanja strukturisanim i zanimljivim studentima. Isto tako, uloga stilova učenja očigledno utiče na reakciju studenata za upotrebu ovog prezentacionog softvera na času (Kunkel, 2004: 194).

U svetlu globalizacije, diplomirani studenti elektrotehnike i softverskog inženjerstva moraju da, između ostalog, budu opremljeni i sposobnostima da upravljaju informacijama na odgovarajući način kako bi opstali u novonastalim turbulentnim vremenima. $U$ tom smislu se Power Point pokazao kao koristan u obezbeđivanju kratkih pregleda koji bi olakšali hvatanje beleški i podvlačenju glavnih tačaka putem fotografija, tabela, grafikona, dijagrama, filmskih klipova (Brock and Joglekar, 2011: 84). Sem toga, ističe se da se u obrazovanju inženjera često koriste prezentacije kao vid predavanja studentima, a takođe studenti koji se obrazuju za inženjere često prave prezentacije kako bi demonstrirali šta su naučili (Garner and Alley 2013: 1564). U literaturi se ističe da inženjerski fakulteti često zahtevaju od studenata da kreiraju prezentacije o svojim projektima kao jedan od načina da nauče sadržaj tog projekta (Aippersbach, Alley and Garner 2013: 1).

U narednom delu, pogledaćemo teorijski okvir koji nam je poslužio kao polazna tačka za naše istraživanje, a zatim i konkretno istraživanje. No, pre nego što opišem istraživanje koje sam sproveo pogledaću i teorijski okvir iz literature, kao i prethodna istraživanja na koja se nadovezujem.

\subsection{Teorijski okvir, reforma nastave engleskog jezika struke}

\subsection{Power Point u nastavi - kratak pregled literature}

U ovom delu pogledaćemo kako se Power Point prezentacije tretiraju u relevantnoj literaturi. Različite studije dovode u fokus različite aspekte upotrebe Power Point prezentacija. Korisnost Power Point prezentacija se konstantno osporava, ali i pristalice i protivnici imaju nedovoljno empirijskih dokaza (Savoy, Proctor and Salvendy, 2009: 858). Pa tako, pojedini autori ispituju nastavnu efikasnost u vezi sa brojem i gustinom Power Po- 
int slajdova, kao i upotrebu vizuelnih sredstava i ostalih netekstualnih elemenata u okviru slajdova prezentacije, a potom predlažu najbolju praksu za upotrebu slajdova Power Point prezentacije (Brock and Joglekar, 2011: 85-94).

Neki autori se fokusiraju na konkrete probleme u vezi sa Power Point prezentacijama. Pojedini autori smatraju da rasprostranjeno usvajanje Power Point slajdova i pomoćnih materijala-hendautova može da pomogne studentima da zabeleže ključne stvari, ali samo ukoliko mogu da prepoznaju ključne znake koje ih identifikuju (Huxham, 2010: 1). S druge strane, pojedini autori se bave načinom informisanja uz pomoć novih tehnologija i preoblikovanjem percepcije i delovanja. $U$ tom smislu, bave se i dubljim heremeneutičkim, pedagoškim i egzistencijalnim implikacijama integrisanja tehnologije u učionicu (Adams, 2007: 229).

Pored egzistencijalnih i hermeneutičkih implikacija u pedagoškom kontekstu, autori se bave i konkretnim empirijskim istraživanjem da li i u kojoj meri upotreba Power Point prezentacija vodi ka boljim ocenama u odnosu na ostale vidove predavanja (Bartsch and Cobern 2003: 77-86). U reprezentativnoj literaturi, iznose se nalazi da je naglašavanje na vizuelnoj komponenti u okviru Power Point prezentacija pomoglo studentima da se bolje prisete predavanog gradiva (Szabo and Hastings 2000: 176), a prisećanje jeste svakako bitno u procesu usvajanja. Autori posvećuju dužnu istraživačku pažnju i istražuju da li studenti posmatraju Power Point prezentacije kao inovativni stimulans i u kojoj meri je ovo percipiranje novine povezano sa studentovim samovrednovanjem učenja (Burke and James 2008: 277-296).

Ovde je zanimljivo i istraživanje koje upoređuje tri različita stila predavanja, a prednost se daje tradicionalnim predavanjima, uz napomenu da studenti cene inovacije koje se nude u okviru inovativnih načina prezentovanja gradiva (Stephenson, Brown and Griffin 2008: 640-651). Power Point prezentacije se sagledavaju i iz ugla stilova učenja u kontekstu visokoškolske nastave $\mathrm{i}$ to $\mathrm{u}$ teorijskom okviru višestrukih inteligencija (Cox 2008: 1-13). Pojedini autori mere stopu uspešnosti studenata na testovima nakon izlaganja predavanjima pomoću Power Point prezentacija, pa iznose da preporučuju veću upotrebu Power Point-a u okviru nastavnog materijala (Lowry 1999: 18-21). 
Naravno, u literaturi se ne prenebregavaju i ograničenja upotrebe Power Point prezentacija i to u vezi sa efikasnošću i stavovima studenata prema ovom medijumu, ali se i u tim studijama iznose pozitivna iskustva, motivacija studenata, kao i dobri rezultati koje studenti postižu (npr. Susskind 2008: 1228-1239). Ipak, i pored svih nedostataka i mana, u literaturi preovlađuje pozitivno mišljenje i pozitivan stav prema upotrebi Power Point prezentacija u nastavnom procesu. $U$ jednom istraživanju se ističe da su studenti, kojima je inicijalno predavano putem Power Point prezentacija, postali manje motivisani kada su predavanja poprimila tradicionalni format (Susskind 2005: 213). Takođe, iznose se pozitivna iskustva i prilikom upotrebe Power Point hendautova koji utiču na bolje hvatanje beleški i organizovanje učenja (Noppe 2007: 2). Konačno, upotreba Power Point projekata u nastavi smatra se i integrisanim elementom simulacije, pa se, sledstveno tome, može smatrati alatom nastavne komunikacije koji se može iskoristiti za praktično kreiranje priručnika, informativnih izveštaja i grafikona (Cyphert 2004: 82).

Kao što smo videli iz ovog kratkog i nepretencioznog pregleda relevantne literature o upotrebi i korišćenju Power Point prezentacija u nastavnom procesu uopšte, ali i u nastavi stranog jezika, iskustva su uglavnom pozitivna. Autori, u većini slučajeva, navode povećanje motivacije kod studenata, kao i bolje rezultate prilikom korišćenja Power Point prezentacija, bilo u vidu studentskih projekata, bilo u vidu oblika nastave. $U$ narednom delu pogledaćemo kratak osvrt na reformu nastave u svetlu Bolonjske deklaracije i reperkusije na strukturu i nastavu engleskog jezika struke.

\subsection{Reforma nastave engleskog jezika struke na Elektrotehničkom fakultetu u Beogradu}

Nakon zvaničnog usvajanja i primene principa Bolonjske deklaracije na Elektrotehničkom fakultetu Univerziteta u Beogradu 2003. godine, uveo sam drastične promene u postojeći kurikulum svih kurseva engleskog jezika struke, ili preciznije engleskog jezika elektrotehničkog registra. Najpre sam predmete podelio na šest odelitih predmeta/kurseva (Engle- 
ski za elektrotehniku 1, 2, 3, 4, 5 i 6), a potom sam uveo potupuno nove predmete koji do tada nisu postojali na Elektrotehničkom fakultetu, a to su Engleski za softversko inženjerstvo - niži kurs i Engleski za softversko inženjerstvo - viši kurs.

lako se uvođenje potpuno novih predmeta i osvežavanje postojećih predmeta engleskog jezika koji pripada elektrotehničkom registru i registru softverskog inženjerstva može smatrati dobrodošlom mogućnošću za ponovnu evaluaciju nekih aspekata poboljšavanja engleskog jezika struke i engleskog jezika za akademske potrebe, konkretni problemi za koje sam smatrao da na njih treba obratiti posebnu pažnju bili su brojni (na primer, neka od pitanja koja sam sebi postavio bila su: Kako obezbediti osnovu za potpuno novi princip bolonjske učionice? Kako premostiti jaz između „starog" sistema koji je podrazumevao rad u velikim grupama studenata i „novog" bolonjskog sistema u okviru koga sam dobio manje grupe studenata u prilično manjim grupama? Kako pobljšati i unaprediti komunikativne aktivnosti? Kako ću motivisati moje studente, buduće diplomirane inženjere elektrotehnike i softverkog inženjerstva da predstave na najbolji i najoptimalniji mogući način koliko su dobro ovladali nastavnim materijalom i nastavnim gradivom kojim sam ih prethodno snabdeo i prezentovao ga?). Ovo su samo neka od pitanja na koja sam naišao i koja sam sebi postavio neposredno pred početak školske 2004/2005. godine, kada je bolonjski način studiranja u potpunosti zaživeo na Elektrotehničkom fakultetu u Beogradu.

S obzirom da je u globalizovanom svetu poraslo interesovanje za usko specijalizovane registre engleskog jezika (npr. engleski za medicinske svrhe, engleski za elektrotehniku, engleski za mašinsku tehniku, itd), osmislio sam novi plan i program koji se razlikovao od prethodnih programa na Elektrotehničkom fakultetu u Beogradu u nekoliko bitnih parametara, od kojih mi je najvažnija bila potreba mojih studenata elektrotehnike i softverskog inženjerstva za engleskim jezikom uslovljena ulogom engleskog jezika u njihovoj struci, odnosno, ulogom engleskog za elektrotehniku i softversko inženjerstvo. Ono što je vrlo bitno jeste da i studenti, koji slušaju kurseve engleskog jezika za elektrotehniku i softversko inženjerstvo ne padaju u zabludu da se njihov kurs stučnog engleskog sastoji u učenju ograničenog repertoara stručnih termina iz oblasti elektrotehni- 
ke i softverskog inženjerstva. Imajući sve ovo u vidu, počevši od školske 2004/2005. godine pa do danas koristim Power Point projekte kao bitan sastojak u vrednovanju i evaluaciji znanja engleskog za elektrotehniku i softversko inženjerstvo. U narednom delu opisaću konkretno Power Point projekte u nastavi engleskog jezika na Elektrotehničkom fakultetu u Beogradu.

\subsection{Power Point projekti u nastavi engleskog jezika na Elektrotehničkom fakultetu}

Pošto sam uzeo u obzir sve izmene nastavnog programa $u$ širem smislu, ali i nastavnog programa u užem smislu, koje su nastupile 2004. godine, te iste školske godine u okviru predispitnih obaveza za engleski jezik uveo sam studentske projekte u obliku Power Point prezentacija u dva jezička registra: engleskom za elektrotehniku i engleskom za softversko inženjerstvo. Naravno, prethodno sam sproveo analizu komunikativnih potreba koja je dobro opisana u literaturi (vidi: Carroll 1980: 19-25) U ovom radu, objasniću ulogu Power Point prezentacija u nastavnom procesu, ali i u procesu usvajanja engleskog za akademske svrhe i engleskog za specifične svrhe.

$U$ metodici nastave opšteg engleskog jezika, ali i engleskog jezika struke, smatra se da su vizuelni oblici komunikacije izuzetno važni u procesu učenja i usvajanja, a posebno se ističe da su vizuelna sredstva vrlo važna u tehničkoj komunikaciji (Hutchinson and Waters 1992: 7). Pored toga, vizuelna sredstva i vizuelni oblici čini se da su relevantni u priručnicima za engleski jezik, udžbenicima za engleski jezik, kao i referentoj literaturi. S obzirom na to da je studentima potrebno poznavanje formalnog i stručnog jezika koji koriste njihove kolege u zemljama engleskog govornog područja, želeo sam da koristim predloge iz reprezentativne ESP literature (npr. Glendinning and McEwan 1993), a prema kojoj, aktivnosti treba da obuhvataju: 1. prezentaciju nastavnog gradiva, 2. uvežbavanje i 3. produkciju. Možda je najzanimljiviji vid projekata zapravo krajnji proizvod, koji je neka vrsta s opšteg engleskog i engleskog jezika struke, ili preciznije engleskog za elektrotehniku i softversko inženjerstvo. 
Takođe, pošao sam od stava, koji se iznosi u literaturi, a prema kome se očekuje da nastavnici usvoje zajedničko učenje u malim grupama u svoju nastavnu praksu, naročito s obzirom na to što se ovakav vid nastave prepoznaje kao efikasan način učenja (Dooly and Masats 2008: 27). Nakon što se iskristalisala i jasno definisala upotreba Power Point projekata posle dvanaest školskih godina tokom kojih sam ih primenjivao u nastavi engleskog jezika struke na Elektrotehničkom fakultetu u Beogradu, mogao bih da podelim vrste projekata-prezentacija koje su zadavane studentima u dve grupe. Kako bismo ilustrovali neke od naslova projekata, pogledaćemo grupe i teme projekata koje su obično zadavane studentima.

Prva grupa studenata dobila je specifične teme koje se odnose na gradivo koje se izučava iz stručnih predmeta na Elektrotehničkom fakultetu u Beogradu, a neke od tih tema su: Exceptions and GUI in Object-Oriented Programming, Transmission Lines and Waveguides in Electromagnetic Fields and Waves, LoS in MRLD, Principle of Superposition in Optoelectronics, Constant False Alarm Rate Detection in RADS, Dispersion Flattened and Dispersion Compensating Fibres, Vector Table Initialisation in Assembly Programming, Feedback Signal Acquisition in Electric Drives, Extending Classes, Interfaces, Numerical Differentiation and Integration in Numerical Mathematics, Overvoltage and Insulation Coordination, Radio Navigation Systems, Monte Carlo Methods in Probability and Statistics, CW Modulation Systems in Communications, Control of Power Converters, Construction of Power Transformers, Protection Elements of Power Systems, Classification of High Voltage Equipment, CAD in Power Systems.

Iz navedenih osamnaest tema za Power Point projekte, može se videti da su ove teme prilično usko specijalizovane i spadaju istovremeno u gradivo koje studenti izučavaju u okviru kurseva na osnovnim (dodiplomskim) studijama, ili preciznije u okviru modula, kako ih zovemo u skladu sa bolonjskom terminologijom. Međutim, postoje i teme koje se uzimaju iz reprezentativne ESP literature, ili preciznije iz udžbenika engleskog jezika struke i kurseva posvećenih engleskom jeziku za elektroniku, računarstvo i tehničku komunikaciju.

Druga grupa studenata je dobila teme uzete iz specijalizovanih udžbenika (a to su sledeće reference: Boeckner and Charles Brown 1993; Đurić 2014; Fitzgerald, McCullagh and Tabor 2011; Glendinning and McEwan 
1993; Hutchinson and Waters 1993; Ibbotson 2008; Ibbotson 2009; Remacha Esteras 2008; Remacha Esteras and Fabré 2007; Smith 2014), a radi ilustracije, navešću par tema: Test and Repair Instruments, Atomic Physics and Nuclear Physics, Portable Computers, Input and Output Devices, Measuring Instruments, Storage Devices, Shapes and 3D Features in Engineering, Oscilloscope, Technical Development, Energy Resources, Chatting and Videoconferencing, Electricity Distribution, Remote Control, Programming Languages.

Ukoliko uporedimo ova dva skupa tema, odmah primećujemo da su specifičnije stručne teme usko specijalizovane i profilisane u skladu sa stručnim predmetima koji se izučavaju na Elektrotehničkom fakultetu u Beogradu. Sledstveno tome, usledile su dve vrste mini projekta, jedan na opštije teme, a drugi na specifičnije stručne teme. $S$ druge strane, opštije teme su uzete iz ESP udžbenika navedenih u literaturi, a ovi udžbenici imaju tendenciju da se fokusiraju na opštije oblasti, pa samim tim, i opštije teme iz oblasti elektrotehnike i softverskog inženjerstva. Svakako, ne treba zanemariti ni relevantnost ovih opštijih tema, zato što one fuzionišu opšti engleski i engleski jezik struke na najbolji mogući način, obezbeđujući dokaz da opšti engleski i engleski za specifične svrhe nisu u potpunosti razvedeni. U narednom delu, opisaću tipičan algoritam procesa izrade studentskog Power Point projekta.

Nakon što su dobili liste tema, a na osnovu preporuka iz literature (Dooly and Masats 2008: 28), usledile su sledeće faze: 1. odabir teme, 2. planiranje Power Point projekta, 3. iznalaženje relevantnih informacija o odabranoj temi, 4. razvoj i primena plana, 5. prezentovanje i evaluacija autputa i njihovog sopstvenog napora. Posle dve godine primene Power Point projekata napravio sam dve varijacije u redosledu. Uslovno rečeno, ove dve varijacije nazvao bih: tipičan redosled i specifičniji redosled.

Tipični redosled bi se mogao prikazati kao sledeći algoritam:

- Odabir teme

- Individualni rad na mini projektu

- Objedinjavanje rezultata

- Rad u mini grupama od 3 do 5 studenata

-Eksperimentalna verifikacija projekta

- Prezentovanje relevantnih nalaza 
- Izveštaj o napredovanju putem elektronske pošte

- Feedback nastavnika

Specifičniji redosled zahteva i veći stepen angažovanja nastavnika, a mogao bi se prikazati kao sledeći algoritam:

Nastavnik

- Uvod u opštu ili specifičnu temu (unapred pripremljenu)

-Uzorak integralnog teksta iz odabrane oblasti na autentičnom materijalu

\section{Student}

- Prikupljanje relevantnih informacija

- Razrada ideja i specifičnog jezika (specifične gramatičke strukture, stil, registar)

- Izveštavanje o napredovanju praćeno grafikonom performansi putem elektronske pošte

Takođe je bitna interakcija na relaciji „student - nastavnik“ koja obuhvata sledeće komponente:

- Slanje nacrta mini projekta - prezentacije

- Elektronski feedback

- Zeleno svetlo za izradu projekta

- Izrada Power Point prezentacije na konkretnu, prethodno istraženu temu

- Studentske prezentacije

- Mini predavanja u grupama od 3-5 studenata u trajanju od 10-15 minuta

- Mini predavanja - redefinisanje komunikativnog znanja opšteg jezika

-Prethodno stečena znanja i jezičke veštine za prezentovanje mini projekta

- Konsolidacija

- Fuzija znanja iz stručnih predmeta i akademskih modula

- Upotreba ekspertskih sistema

Pošto odaberu odgovarajuću temu, studenti započinju najpre rad na mini projektima individualno, a zatim i u timu. Ponekada se očekuje da studenti eksperimentalno verifikuju svoje pretpostavke i da predstave 
relevantne nalaze do kojih su došli u toku izrade projekta. O svom napredovanju, kao i svim nedoumicama i pitanjima koje imaju, studenti se konsultuju sa nastavnikom putem elektronske pošte. Takođe, tokom rada na projektu, studenti šalju izveštaj o napredovanju. Ova elektronska komunikacija na relaciji „student - nastavnik; nastavnik - student“ predstavlja interakciju putem elektronske pošte koja se može posmatrati ne samo kao vid poboljšanja komunikaciji između nastavnika i studenata, već se stiče utisak da nastavni proces dobija jedan sasvim novi smisao.

U ovim mejlovima, moji studenti obično traže i očekuju konkretan feedback, kao i specifične konsultacije i konkretne savete. Konkretna uputstva koja im dajem u vezi sa projektima uglavnom su usidrena u reprezentativnoj ESP literaturi (Hutchinson and Waters 1992), kao i literaturi o učenju jezika putem kompjutera (Levy 1997). Najpre im šaljem materijale koji bi mogli da im pomognu u izradi projekta, a zatim i uzorke autentičnog engleskog na specifičnim materijalima (projektna dokumentacija, patenti, izveštaji o konkretnoj laboratorijskoj vežbi, itd). Zatim se od studenata očekuje da prikupe relevantne informacije u vezi sa odabranom temom, da porade na specifičnom načinu izražavanja, elektrotehničkom registru i na idejama koje će proširiti u toku rada na projektu. Studenti podnose pisani izveštaj o svakoj etapi rada na projektu, koji je obavezno propraćen grafikonom uspešnosti i performanse, blok dijagramima i tehničkim opisima projekta. U ovom segmentu izrade projekta, studentima se pruža mogućnost da koriste sopstveno znanje stečeno iz drugih predmeta koji se izučavaju na Elektrotehničkom fakultetu koje fuzionišu sa onim što su naučili i usvojili tokom mojih časova engleskog jezika.

Nakon uspešne implementacije svih koraka, koje sam prethodno opisao i/ili prikazao putem algoritma, studenti šalju nacrte svojih projekata. Oni se stimulišu da koriste ekspertske sisteme, koji se izučavaju na elektrotehničkim odsecima, kao i na softverskom inženjerstvu. Čim pošalju nacrt projekta, studenti dobijaju pisani elektronski feedback, a onda dobijaju zeleno svetlo da kreiraju Power Point prezentaciju na konkretnu podtemu. Prema prethodno utvrđenom rasporedu studenti održe mini-predavanja (u ukupnom trajanju između 10 i 15 minuta) praćena kreativno generisanim Power Point prezentacijama.

Čini mi se da su ova studentska mini-predavanja relevantna zato što radikalno redefinišu komunikativno opšte znanje jezika na taj način što 
ovi Power Point projekti i mini-predavanja navode studente da koriste i upotrebljavaju sve svoje jezičke veštine koje su do tog trenutka stekli da bi na najbolji način prezentovali Power Point projekat koji su prethodno temeljno pripremili.

U narednom delu, pogledaćemo dobre strane upotrebe Power Point projekata u nastavi engleskog za elektrotehniku i softversko inženjerstvo.

\subsection{Diskusija i zaključne napomene}

Dobre strane Power Point projekata u engleskom za elektrotehniku i softversko inženjerstvo bile bi sledeće:

1. Moji student se podstiču i stimulišu da jasno utvrde ciljeve u svojim konkretnim istraživanjima odabrane specifične teme.

2. Power Point prezentacije istovremeno poboljšavaju strukturalne, funkcionalne i tekstualne aspekte opšteg engleskog dok se fokusiraju na engleski za specifične svrhe, tj. engleski jezik struke (u ovom slučaju engleski za elektrotehniku i engleski za softversko inženjerstvo).

3. Studentima se daje kontrola nad redosledom etapa projektnog istraživanja, što, između ostalog, poboljšava i kritičko mišljenje.

4. Studenti se podstiču da koriste specijalizovane ekspertske sisteme, pa se na taj način povezuju znanja engleskog jezika sa njihovim znanjima iz oblasti računarstva i informatike.

5. Studenti elektrotehnike i softverskog inženjerstva bave se svim detaljima „stvarnog“ jezika i stručnog jezika koji koriste elektroinženjeri i softverski inženjeri kojima je maternji jezik engleski.

6. Power Point projekti radikalno redefinišu komunikativno opšte znanje engleskog jezika mojih studenata.

Naravno, ovih šest tačaka su samo neke od prednosti korišćenja Power Point projekata u nastavi engleskog za elektrotehniku i softversko inženjerstvo. Međutim, smatram da je i ovih šest tačaka dovoljno da ilustrujem izvesne prednosti pristupa koji sam implementirao. Naravno, 
nameravam da poboljšam opisani pristup na taj način što ohrabrujem i motivišem studente elektrotehnike i softverskog inženjerstva da kreativno razmišljaju i da razvijaju veštine kritičkog razmišljanja.

U ovom radu, analizirani su i/ili uzeti u obzir sledeći parametri:

- Implikacije uvođenja Bolonje

- Reforma nastavnog plana u širem smislu i nastavnog plana u užem smislu za ESP i EAP na Elektrotehničkom fakultetu u Beogradu

- Implementacija konkretnih promena u vidu mini projekata

- Primena u visokoškolskom kontekstu (uz mogućnost primene u gimnazijama, srednjim stručnim školama, a možda čak i u višim razredima osnovih škola)

- Mogućnost poboljšanja veštine kritičke pismenosti i kritičkog razmišljanja

- Minimalne liste različitih jezičkih zadataka u obliku Power Point prezentacija

- Fuzionisanje znanja engleskog jezika i znanja iz drugih oblasti i stručnih elektrotehničkih predmeta

- Izražavanje ekspertskog znanja na engleskom jeziku

- Upotreba ekspertskih sistema

- Analitičko interesovanje za ostale predmete kroz engleski jezik.

U ovom radu, pokušao sam da osvetlim izvesne implikacije uvođenja promena u nastavni plan u širem i u užem smislu za ESP i EAP na Elektrotehničkom fakultetu u Beogradu. Pored toga, opisao sam stvarnu primenu ovih kurikularnih izmena koje su motivisane zvaničnim usvajanjem Bolonjske deklaracije 2003. godine na Elektrotehničkom fakultetu u Beogradu, kao i uvođenjem ESPB sistema. Putem ilustracije opisujem studentske Power Point projekte koji se bave ili specijalizovanim temama ili pak opštijim temama preuzetim iz postojećih ESP udžbenika za engleski za elektrotehniku i softversko inženjerstvo. Istraživanjem se pokazalo da Power Point prezentacije i studentski projekti radikalno redefinišu komunikativno opšte znanje engleskog jezika, kao i engleskog za elektrotehniku i softversko inženjerstvo fuzionisanjem opšteg engleskog, stručnog engleskog i ekspertskih sistema.

Videli smo da se Power Point projekti, koji predstavljaju svojevrsne simulacije, mogu smatrati održivim, inovativnim rešenjima zasnovanim na 
aktivnom učešću, a istovremeno, ovi projekti predstavljaju jedan vid osposobljavanja za izazovne zahteve novih globalizovanih konteksta učenja i rada. Sve ovo zahteva osmišljavanje novih metoda i tehnika i promišljanje tradicionalnih nastavnih praksi u potrazi za maštovitim i kreativnim metodama koje su primerenije za razvoj budućih inženjera elektrotehnike i softverskog inženjerstva u savremenom globalizovanom društvu.

Uopšteno posmatrano, i metodološki gledano, modeli i metode koji su ovde prezentovani mogu se primeniti i u kontekstu gimnazija, srednjih stručnih škola, a možda i u višim razredima osnovnih škola, barem kada je u pitanju nastava engleskog jezika. Na primer, u kontekstu srednjih stručnih škola, nastavnici mogu da poboljšaju veštine kritičke pismenosti đaka time što im prethodno unapred daju pripremljene minimalne liste različitih zadataka u obliku Power Point prezentacija. Naravno, ovi konkretni zadaci bi obuhvatili i sadržali takođe i veštine i sposobnosti đaka iz mnogih drugih stručnih predmeta koji se izučavaju u srednjim školama. Ova specifična znanja, preuzeta iz stručnih predmeta, povezala bi izvor znanja iz tih predmeta sa engleskim jezikom na kome bi se prezentacije kreirale. $\mathrm{Na}$ taj način, nastavnici mogu motivisati đake da izraze svoja ekspertska znanja kroz engleski, što bi se moglo smatrati i jednim od krajnih ciljeva u nastavi engleskog jezika, ili preciznije u oblasti EFL, ESL i ESP. Takođe, ove interaktivne mentalne vežbe mogle bi stimulisati analitička interesovanja učenika za ostale predmete kroz engleski jezik.

$\mathrm{U}$ radu smo pokazali da se upotrebom Power Point projekata $u$ nastavi engleskog za elektrotehniku i softversko inženjerstvo na Elektrotehničkom fakultetu u Beogradu pobuđuje interesovanje studenata elektrotehnike i softverskog inženjerstva, koji onda aktivno učetvuju u svim etapama i segmentima projekta, koji može biti simulacija njihovog budućeg radnog okruženja. Na ovaj način, studentima se usađuje inspiracija za daljim radom, i povećava se motivisanost, a sve je ovo potvrđeno rezultatima ankete putem upitnika, kojim je evaluirana uspešnost primene Power Point projekata u engleskom za elektrotehniku i softversko inženjerstvo na Elektrotehničkom fakultetu u Beogradu. Rezultati anonimne ankete pokazali su da su studenti zadovoljni Power Point projektima kao sastavnim delom engleskog za elektrotehniku i softversko inženjerstvo. 


\section{Literatura}

Adams, Catherine. "PowerPoint, habits of mind, and classroom culture." Journal of Curriculum Studies Vol. 38 No. 4 (2006): 389-411. Print.

Adams, Catherine. "On the 'informed use' of PowerPoint: rejoining Vallance and Towndrow." Journal of Curriculum Studies Vol. 39 No.2 (2007): 229-233. Print.

Aippersbach, Shannon Marie, Michael Alley and Joanna K. Garner. "How slide design affects a student presenter's understanding of the content." $120^{\text {th }}$ ASEE Annual Conference \& Exposition. American Society for Engineering Education, pp. 1-10, 2013. Print.

Bartsch, Robert A. and Kristi M. Cobern. "Effectiveness of PowerPoint presentations in lectures." Computers \& Education 41 (2003): 77-86. Print.

Boeckner, Keith and P. Charles Brown. Oxford English for Computing. Oxford: Oxford University Press, 1993. Print.

Brock, Sabra and Yogini Joglekar. "Empowering PowerPoint: slides and teaching effectiveness." Interdisciplinary Journal of Information, Knowledge, and Management, Editor: Eli Cohen, Volume 6, 2011 (2011): 85-94. Print.

Burke, Lisa A. and Karen E. James. "PowerPoint-based lectures in business education: An empirical investigation of student-perceived novelty and effectiveness." Business Communication Quarterly Volume 71, Number 3, (2008): 277-296. Print.

Carroll, Brendan J. Testing Communicative Performance: An Interim Study. Oxford: Pergamon Press, 1980. Print.

Cox, Thomas D. "Learning styles and students' attitudes toward the use of technology in higher and adult education classes." Institute for Learning Styles Journal, Volume 1, Fall 2008, (2008): 1-13. Print.

Cyphert, Dale. "The problem of PowerPoint: Visual aid or visual rhetoric?." Business Communication Quarterly March 2004, 67, 80 (2004): 80-84. Print.

Dooly, Melinda and Dolors Masats. "Russian dolls: Using projects to learn about projects." Greta Journal 16 (2-3) (2008): 27-35. Print.

Đurić, Miloš D. English for Electrical Engineering (Modules 1 and 2). Belgrade: Faculty of Electrical Engineering and Academic Mind, 2014. Print.

Fitzgerald, Patrick, Marie McCullagh and Carol Tabor. English for ICT Studies in Higher Education Studies. Reading: Garnet Education, 2011. Print.

Garner, Joanna K. and Michael P. Alley. "How the design of presentation slides affects audience comprehension: A case for the assertion-evidence approach." International Journal of Engineering Education Vol. 29 No. 6 (2013): 1564-1579. Print.

Glendinning, E. H. and J. McEwan. Oxford English for Electronics. Oxford University Press, Oxford, 1993. Print.

Griffin, Darren K., David Mitchell and Simon J. Thompson. "Podcasting by synchronizing PowerPoint and voice: What are the pedagogical benefits?." Computers \& Education 53 (2009): 532-539. Print. 
Hutchinson, Tom and Alan Waters. Interface - English for Technical Communication Teacher's Guide. Longman, London, 1992. Print.

Hutchinson, Tom and Alan Waters. Interface - English for Technical Communication Student's Book. Longman, London, 1993. Print.

Huxham, Mark. "The medium makes the message: Effects of cues on students' lecture notes." Active Learning in Higher Education 11 (3) (2010): 1-11. Print.

Ibbotson, Mark. Cambridge English for Engineering. Cambridge: Cambridge University Press, 2008. Print.

Ibbotson, Mark. Professional English in Use: Technical English for Professionals. Cambridge: Cambridge University Press, 2009. Print.

Kunkel, Karl R. "A research note assessing the benefit of presentation software in two different lecture courses." Teaching Sociology Vol. 32 (2004): 188-196. Print.

Langran, Pol. Uvod u permanentno obrazovanje. Beograd: Narodni univerzitet Braća Stamenković, 1970. Print.

Levy, Michael. Computer-Assisted Language Learning: Context and Conceptualization. Oxford: Clarendon Press, 1997.

Lowry, Roy B. "Electronic presentation of lectures - Effect upon student performance." University Chemistry Education 3 (1), (1999): 18-21. Print.

Noppe, Illene C. "PowerPoint presentation handouts and college student learning outcomes." International Journal for the Scholarship of Teaching and Learning Vol. 1, No. 1 (2007): 1-13. Print.

Remacha Esteras, Santiago. Infotech - English for Computer Users. Fourth Edition. Cambridge: Cambridge University Press, 2008. Print.

Remacha Esteras, Santiago and Elena Marco Fabré. Professional English in Use: For Computers and the Internet. Cambridge: Cambridge University Press, 2007. Print.

Savoy, April, Robert W. Proctor and Gavriel Salvendy. "Information Retention from PowerPoint ${ }^{\mathrm{TM}}$ and traditional lectures." Computers \& Education 52 (2009): 858867. Print.

Smith, Roger H. C. English for Electrical Engineering in Higher Education Studies - Course Book. Reading: Garnet Education, 2014. Print.

Stephenson, Julia E., Clifford Brown and Darren K. Griffin. "Electronic delivery of lectures in the university environment: An empirical comparison of three delivery styles." Computers \& Education 50 (2008): 640-651. Print.

Susskind, Joshua E. "PowerPoint's power in the classroom: enhancing students' selfefficacy and attitudes." Computers \& Education 45 (2005): 203-215. Print.

Susskind, Joshua E. "Limits of PowerPoint's power: Enhancing students' self-efficiacy and attitudes but not their behavior." Computers \& Education 50 (2008): 1228-1239. Print.

Szabo, Attila and Nigel Hastings. "Using IT in the undergraduate classroom: should we replace the blackboard with PowerPoint?." Computers \& Education 35 (2000): 175-187. Print. 


\author{
Miloš D. Đurić \\ University of Belgrade \\ Faculty of Electrical Engineering
}

\title{
POWER POINT PROJECTS IN ENGLISH FOR ELECTRICAL ENGINEERING AND ENGLISH FOR SOFTWARE ENGINEERING
}

\section{Summary}

This paper describes the actual implementation of Bologna Declaration in English for Specific Purposes at the Faculty of Electrical Engineering, University of Belgrade. More specifically, it describes one aspect of ESP reforms, namely the integration of Power Point projects in English for Electrical Engineering and English for Software Engineering.

Raising students' awareness to the relevant aspects of specialised English topics in Power Point projects is helpful because students feel encouraged and motivated to attempt to engage in similar more specialised projects. This, in turn, helps them develop a better feel for their own field of expertise as future electrical engineers and software engineers. Additionally, the results of my research have shown that utilisation of Power Point projects makes my students more confident and willing to experiment when expressing themselves both in speech and writing in the context of English for Electrical Engineering and English for Software Engineering. In my research, students are presented with preset matrices of technical discourse ingredients that they should employ in their own projects.

My findings point to the conclusion that, along with an enhanced vocabulary that they gain through exploration and research aimed at generating their Power Point project, these projects afford them great language adroitness and flexibility. Furthermore, in the course of the process of exploration and research students feel that Power Point projects seem to be educative and liberating, which again might be an important fact from the methodological point of view.

Key words: Power Point Projects, Power Point Presentations, English for Electrical Engineering, English for Software Engineering, Communicative Performace, Web Tools, Expert Systems. 